Protestantismo em Revista é licenciada sob uma Licença Creative Commons.

http://dx.doi.org/10.22351/nepp.v44i2.3709

\title{
REFLEXÕES SOBRE O PENTECOSTALISMO NO BRASIL E SUA ESTRUTURA LITÚRGICA
}

\author{
Reflections on Pentecostalism in Brazil and its Liturgical Structure
}

\author{
Paulo Júnior* \\ Clodoaldo Sanches Fófano **
}

\begin{abstract}
Resumo:
O presente artigo buscou refletir acerca do culto pentecostal e a sua estrutura litúrgica. Para tanto, apresenta breve reflexão da história do cristianismo. Em seguida discorre sobre o pentecostalismo nos dias atuais e o surgimento desse movimento de avivamento espiritual. Logo depois, discute a prática do culto pentecostal, destacando características, desenvolvimento e ritual litúrgico. Na construção deste artigo realizou-se pesquisa bibliográfica de base qualitativa, considerando as contribuições de teórico como Cairns (1988), Hurlbut (2002), Santos Júnior (2016), entre outros. Estudos recentes mostram que o pentecostalismo é a corrente do cristianismo que mais se propaga nos últimos anos, e se levar em conta o período 1980-2010, o pentecostalismo avançou acima da média de crescimento da população nacional. A partir dessa perspectiva, foi possível observar que o culto pentecostal é bastante peculiar, primando por uma liturgia objetiva, o que facilita o acesso do fiel ao sagrado.

Palavras-chave: Culto pentecostal. Estrutura litúrgica. Cristianismo.
\end{abstract}

\begin{abstract}
:
The present article sought to reflect on the Pentecostal cult and its liturgical structure. For that, it presents a brief reflection on the history of Christianity. He then discusses Pentecostalism in the present day and the emergence of this movement of spiritual revival. Soon after, he discusses the practice of Pentecostal worship, highlighting characteristics, development, and liturgical ritual. In the construction of this article a qualitative bibliographical research was carried out, considering the contributions of the theoretical ones like Cairns (1988), Hurlbut (2002), Santos Júnior (2016), among others. Recent studies show that Pentecostalism is the current of Christianity that has spread the most in recent years, and taking into account the period 19802010, Pentecostalism has advanced above the average growth of the national population. From this perspective, it was possible to observe that the Pentecostal cult is quite peculiar, emphasizing an objective liturgy, which facilitates the access of the faithful to the sacred.
\end{abstract}

[Texto recebido em dezembro de 2017 e aceito em agosto de 2018, com base na avaliação cega por pares realizada por pareceristas ad hoc]

* Doutor. Universidade Cândido Mendes. E-mail:paulojsjunior@hotmail.com

** Mestre em Ciências das Religiões, Faculdade Unida. E-mail: clodoaldosanches@hotmail.com 
Keywords: Worship pentecostal. Liturgical structure. Christianity.

\section{Introdução}

[...] a verdadeira função da religião não é nos fazer pensar, enriquecer nosso conhecimento, $[\ldots]$ mas sim nos fazer agir, nos ajudar a viver. ${ }^{1}$

[...] a liturgia é um índice das atitudes, do estilo de vida, da cosmovisão e da participação social do povo [...] porque reflete um comportamento psicossocial definido, repleto de imagens socioculturais, com um conteúdo étnico concreto e com uma clara visão da igreja e da sociedade. ${ }^{2}$

Estudos recentes mostram que o pentecostalismo é a corrente do cristianismo que mais se propaga nos últimos anos, e se levar em conta o período 1980-2010, o pentecostalismo avançou acima da média de crescimento da população nacional ${ }^{3}$. Diante disso, Teólogos, Filósofos, Sociólogos, Historiadores e diversos estudiosos da religião afirmam que a América Latina oferece ao pentecostalismo um ambiente propício para seu crescimento e desenvolvimento ${ }^{4}$.

Sendo assim, pretende-se, nesta pesquisa, por meio de uma visão analítica e reflexiva responder à seguinte questão-problema: De que maneira o culto pentecostal cresce por meio de sua estrutura litúrgica? Essa análise traz consigo como objetivo geral refletir acerca do culto pentecostal e a estrutura liturgia desse movimento. Já como objetivos específicos foi necessário: 1) Apresentar breve reflexão da história do cristianismo. 2) Discorrer sobre o pentecostalismo nos dias atuais e a gênese desse movimento de renovação.

3) Discutir a prática do culto pentecostal, destacando características e desenvolvimento do mesmo em terras brasileiras.

Esse estudo é importante, uma vez que o Brasil é uma das nações mais religiosas do mundo, pois podemos observar o dinamismo do pentecostalismo brasileiro e como o fiel se relaciona com esse sistema religioso. Para a realização deste artigo optou-se em utilizar a metodologia conhecida como levantamento de dados especializado, através de pesquisas em periódicos e livros que discutem a presente temática. Essa metodologia foi escolhida, uma vez que possibilita trabalhar com informações acadêmicas seguras ${ }^{5}$.

DURKHEIM, Émile. As Formas Elementares da Vida Religiosa. São Paulo: Martins Fontes, 1996.

2 COSTAS, Orlando. El protestantismo en América Latina hoy: Ensayos del camino. San José: INDEF, 1975. p. 8.

3 SANTOS JÚNIOR, Paulo Jonas dos; ROSA, André Luis da. Experiência religiosa: da Reforma Protestante ao avivamento pentecostal. Encontros Teológicos: Reforma ontem e hoje, Florianópolis, v. 31, n. 2, p. 235-252, ago. 2016. Disponível em: <facasc.edu.br>. Acesso em: 21 dez. 2017.

4 SANTOS JÚNIOR; ROSA, 2016, p. 236.

5 FONTELLES, Mauro José et al. Metodologia da pesquisa científica: diretrizes para a elaboração de um protocolo de pesquisa. Ciências Saúde, [s.i.], v. 1, n. 1, p.1-8, ago. 2009. Disponível em: <https://cienciassaude.medicina.ufg.br/up/150/o/Anexo_C8_NONAME.pd>. Acesso em: 21 dez. 2017. 
Três seções compõem o desenvolvimento desta pesquisa. A primeira faz apresentação da trajetória do surgimento do cristianismo na época de Jesus até a reforma protestante. Na seguinte seção, discorre sobre o pentecostalismo em sua origem e propagação como movimento de avivamento e busca pelas evidências do poder do Espírito Santo registradas no livro de Atos. Em seguida discuti a organização litúrgica do universo do culto pentecostal brasileiro e o dinamismo de tal movimento que consegue alcançar ambientes em que outros segmentos de mesmo princípio, não se estabelecem.

Para construção do referencial teórico deste artigo, foram utilizados os seguintes autores: Cairns (1988); Costas (1975); Durkheim (1996); Fontelles (2009); Gombrich (2000); Hurlbut (2002); Mariano (2008); Mondin (2014); Oliveira (2016); Oliveira \& Campos (2016); Santos Júnior (2016); Santos Júnior \& Rosa (2016). Além da Bíblia (2010) e informações do canal de notícias BBC (2017).

\section{Breve reflexão histórica}

O cristianismo é a maior religião do mundo ${ }^{6}$. Em seus primórdios, de acordo com Hurlbut, iniciou com:

Um pequeno grupo de judeus crentes no seu Senhor, elevado como Messias-Rei de Israel, esperou algum tempo em Jerusalém, sem considerar inicialmente a existência de uma igreja fora dos limites do Judaísmo. Contudo, alargaram gradualmente seus conceitos e ministério, até que sua visão alcançou o mundo inteiro [...].7

Um pequeno movimento que iniciou com um homem que pregava as verdades do Judaísmo de uma maneira mais humanizada, ganhou rapidamente o mundo antigo e, após dois mil anos ainda não foi superado. Igualmente, Cristo priorizou a proclamação de seus ensinamentos aos judeus de Jerusalém. Tal fato pode ser evidenciado até mesmo por intermédio de um estudo superficial do livro de Atos ${ }^{8}$. Para Cairns:

[...] esta é a ordem seguida pela Igreja primitiva. O evangelho foi primeiro proclamado em Jerusalém por Pedro no dia de Pentecostes; depois foi levado pelos cristãos judeus a outras cidades da Judéia e da Samaria. Desse modo a Igreja foi primeiramente judia e existiu dentro do judaísmo. ${ }^{9}$

O sistema de crenças judaicas era bastante complexo e na época de Jesus, figura central do cristianismo, as correntes interpretativas da Lei mosaica e dos profetas de Israel

6 BBC. Após cristãos e mulçumanos, sem-religião são $3^{\circ}$ maior grupo no mundo. Disponível em: http://www.bbc.com/portuguese/noticias/2012/12/121218_religioes_mundo_mm. Acesso em: 26 ago. 2017.

7 HURLBUT, Jesse Lyman. História da Igreja Cristã. Editora Vida: São Paulo, 2002. p. 15.

8 Cf. BÍBLIA. Português. Nova Bíblia Viva. João Ferreira de Almeida. São Paulo: Mundo Cristão, 2010.

9 CAIRNS, Earle E. O cristianismo através dos séculos: uma história da igreja cristã. Sociedade Religiosa Edições vida Nova: São Paulo, 1988. p. 45. 
não eram poucas, pelo contrário, na realidade diversos mestres e rabis defendiam diferentes posições quanto à maneira correta de se praticar os desígnios divinos ${ }^{10}$.

Nesse cenário, o Messias do Cristianismo aparece ensinando, porém, enquanto a corrente prevalecente da época levava os fiéis a uma prática vazia da religião, baseada na simples repetição dos preceitos já lançados por Moisés, Jesus lança as bases de seus ensinamentos sobre uma nova interpretação, mais humana ${ }^{11}$. A partir de então, os ensinamentos de Jesus ganham a população da época, e com sua morte, seus seguidores continuam a levar a revolucionária visão do Mestre ${ }^{12}$. Na concepção de Hurlbut essa:

[...] visão alcançou o mundo inteiro, para ser levado aos pés de Cristo. Sob a direção de Pedro e Paulo e seus sucessores imediatos, a igreja foi estabelecida no espaço de tempo de duas gerações, em quase todos os países, desde o Eufrates até o Tibre, desde o Mar Negro até o Nilo. O primeiro período terminou com a morte de João, o último dos doze apóstolos, que ocorreu, conforme se crê, cerca do ano 100.13

Durante os anos que sucederam a crucificação de Jesus, mais precisamente até o quarto século, os cristãos viveram de maneira marginalizada, em certos momentos, tendo que enfrentar a dura perseguição dos romanos, que como praticantes de um sistema religioso politeísta não conseguiam mensurar a mensagem proselitista do cristianismo, já em outras situações, os cristãos recebiam do Estado à autorização para suas práticas religiosas. Até que nessa época, o imperador Constantino estabeleceu a Igreja Cristã como um poder no Estado, o que impulsiona o crescimento dessa religião e a torna protagonista da história europeia ${ }^{14}$.

Durante a idade média, o cristianismo se mistura com a política romana. A Igreja Cristã cede aos encantos do vasto Império. A mensagem que outrora era celeste e pura torna-se misturada por desejo de poder. Assim, a Igreja una não consegue resistir e começa se dividir. Gritos em favor de um retorno à palavra bíblica começam a ser ouvidos no âmbito da Igreja. Enquanto isso, o governo da Igreja deixa-se levar, e através de concílios, encíclicas e resoluções, chancelam o distanciamento da Igreja à sua mensagem original ${ }^{15}$.

Até que 31 de outubro de 1517, aquilo que o Grande Cisma anunciou em 1054, vem à tona. Na véspera do dia de Todos os Santos, uma grande celebração da Igreja na época, Martinho Lutero se põe frente à porta da igreja de Wittenberg e proclama uma palavra inflamada, clamando ao povo que olhe para a Palavra bíblica e retorne para a simplicidade do Evangelho ${ }^{16}$. Conforme Cairns:

10 SANTOS JÚNIOR, Paulo Jonas dos. Histórico da música sacra: do antigo testamento ao culto pentecostal. Azusa: Revista de Estudos Pentecostais, Joinville, v. 8, n. 1, p.95-116, maio 2017. Semestral. Disponível em: <http://azusa.faculdaderefidim.edu.br/index.php/azusa/article/view/159/115>. Acesso em: 01 out. 2017.

11 SANTOS JÚNIOR, 2017, p. 97.

12 SANTOS JÚNIOR, 2017, p. 101.

13 HURLBUT, 2002, p. 16.

14 GOMBRICH, Ernst Hans. A História da Arte. LTC: São Paulo. 2000. p. 133.

15 MONDIN, Battista. Curso de Filosofia. vol. 2. Paulus: São Paulo. 2014. p. 30.

16 MONDIN, 2014, p. 33. 
Alguns fatores tornaram inevitáveis a Reforma. Entre muitos, pode-se destacar: A relutância da Igreja Católica Romana medieval em aceitar as mudanças sugeridas por reformadores sinceros como os místicos, Wycliffe e Huss, os líderes do concílio reformadores e os humanistas; o surgimento das nações-estados, que se opuseram ao poderio universal do papa e a formação da classe média, que se revoltou contra a remessa de reservas para Roma. ${ }^{17}$

A palavra bíblica ecoou por toda Europa, e o evento que ficou conhecido como a Reforma Protestante gerou um movimento de rompimento, em que diversos países romperam com o domínio religioso de Roma e apoiaram as suas respectivas igrejas nacionais ${ }^{18}$. Após o movimento da Reforma Protestante, diversas denominações se originam por todo o mundo e o Cristianismo passa a ficar cada vez mais plural e menos centralizado ${ }^{19}$.

Dessa maneira a identidade religiosa medieval cedeu espaço, no início do século XVI, à variedade religiosa. Com isso, a autoridade da Igreja Romana foi substituída pela autoridade bíblica, que se tornou um livro de leitura livre a qualquer pessoa. Logo, os modelos estáticos da cultura medieval foram substituídos pelos padrões dinâmicos de uma sociedade moderna.

Dentro desse novo perfil social/cristão, o crente se tornou seu próprio sacerdote e condutor da sua vida religiosa em comunhão com Jesus que representa o Sumo Sacerdote, como ressalta Hebreus 2: $17^{20}$. Assim sendo, o cristão é conduzido à reverência quando percebe a mão de Deus nas dificuldades dos homens daquele tempo.

7 CAIRNS, 2002, p. 221.

18 SANTOS JÚNIOR; ROSA, 2016, p. 236.

19 MONDIN, 2014, p. 34.

20 BÍBLIA, 2010, p. 1001. 


\section{O pentecostalismo nos dias atuais}

O movimento pentecostal, no formato que conhecemos hoje, teve sua origem nos EUA no início do século $X X$, através das reuniões de avivamento e busca pelas evidências do poder do Espírito Santo registradas no livro de Atos dos Apóstolos ${ }^{21}$. O Concílio Nacional das Assembleias de Deus na América do Norte surgiu como resultado desse movimento religioso, que se espalhou, rapidamente por todo mundo. Presididas por William Joseph Seymour, as reuniões aconteciam em um local onde havia funcionado uma Igreja Metodista Episcopal ${ }^{22}$. Os fiéis possuíam uma imensa cede espiritual que resultava em grandes reuniões de oração. Como ressalta Hurlbut:

Como resultado das atividades desses grupos de crentes, produziram-se
avivamentos em vários lugares nos Estados Unidos e na Europa. Caracterizavam-se
esses movimentos por um intenso fervor de evangelização e um profundo espírito
de oração. Da mesma forma dava-se ênfase aos dons espirituais e à sua operação,
inclusive cura divina, e falar em outras línguas como sinal de recepção do batismo
do Espírito Santo. ${ }^{23}$

Os acontecimentos característicos do culto pentecostal são principalmente: o falar em línguas estranhas, curas, profecias, visões, etc. Na realidade, ao longo da história do cristianismo esses fenômenos sempre ocorreram, porém não de maneira frequente como no movimento pentecostal atual ${ }^{24}$. Além disso, em relação ao zelo missionário despertado pelo movimento, cabe destacar que tal atitude era baseada na profunda crença de que Jesus está voltando e os crentes batizados no Espírito Santo possuíam a missão de cumprir o "ide", como orienta Jesus aos discípulos no evangelho de Marcos 16:1525.

Esse movimento, que floresceu em terras americanas, influenciou pregadores e líderes de todo o mundo e espalhou a semente de um cristianismo avivado, cuja relação do fiel com o divino pode ser experimentada e sentida através de cultos e reuniões de oração. Por isso, a origem do movimento pentecostal não pode ser atribuída a uma pessoa específica, visto que as manifestações espirituais aconteciam simultaneamente em diversos locais. A fim de justificar tal ocorrência, Hurlbut afirma que

um ministro evangélico chamado Daniel Awrey recebeu o batismo do Espírito Santo, em sua plenitude pentecostal em janeiro de 1890, na cidade de Dalaware, Estado de Ohio, América do Norte. Um grupo de crentes pentecostais realizou uma convenção em 1897, na nova Inglaterra. Mais ou menos na mesma época, manifestou-se um avivamento no estado de Carolina do Norte. No estado de Tennessee, segundo testemunho de Clara Smith, que mais tarde foi missionária no Egito. Havia no ano de 1900 cerca de quarenta ou cinquenta pessoas batizadas com

21 Cf. BÍBLIA, 2010.

22 OLIVEIRA, David Mesquiati de. Diaconia Transformadora. Anais do Congresso Internacional de Teologia, São Leopoldo, v. 1, n. 1, p.621-635, dez. 2012. Disponível em: <http://www.anais.est.edu.br/index.php/congresso/article/view/94/45>. Acesso em: 26 ago. 2017, p. 622.

23 HURLBUT, 2002, p. 221.

24 MESQUIATI, 2012, p. 621.

25 Cf. BÍBLIA, 2010, P. 835. 
o Espírito Santo. No mesmo ano manifestou-se um avivamento pentecostal entre um grupo de crentes de nacionalidade sueca na cidade de Moorhead, estado de Minnesota, cujos resultados são notados ainda na atualidade. ${ }^{26}$

Foi assim que se formavam as assembleias de crentes que mais tarde reuniramse e formaram o Concílio Geral. Muitos daqueles que observavam as manifestações, creram e humilharam-se diante da presença de Deus, buscando o Batismo com o Espírito Santo acompanhado do sinal de falar em línguas. De tal modo, a mensagem pentecostal, por meio da palavra oral e escrita, espalhou-se por todos os lados e recebeu o nome de Movimento. Portanto, por esse motivo, o termo "Movimento Pentecostal", passou a nomear todos os grupos de crentes que enfatizavam a busca pelo Espírito Santo, seguido pelo sinal de falar em outras línguas, como inspiração divina.

\section{O culto pentecostal brasileiro}

A hegemonia cristã no país é algo observado desde o primeiro censo do IBGE em 1872, quando o número de Católicos foi registrado como 99,7\% da população ${ }^{27}$. Nos censos que foram realizados posteriormente, apesar de um decréscimo considerável na quantidade de católicos, o número geral de cristãos ainda continua sendo muito elevado, e um dos principais fatores para essa mudança no cenário cristão é o fortalecimento do pentecostalismo brasileiro. Na compreensão de Mariano:

Desde os anos 50, o Pentecostalismo cresce muito no Brasil. Mas sua expansão acelera-se acentuadamente a partir da década de 1980, momento em que esse movimento religioso passa a conquistar igualmente crescente visibilidade pública, espaço na tevê e poder político partidário. Segundo os Censos Demográficos do IBGE, havia 3,9 milhões de pentecostais no Brasil em 1980, 8,8 milhões em 1991 e 17,7 milhões em 2000.28

O Brasil e a América Latina ofereceram ao pentecostalismo um ambiente propício para seu desenvolvimento. Como segmento que valoriza bastante a fé dos fiéis, o pentecostalismo tem crescido de maneira considerável nas Américas do Sul e Central ${ }^{29}$. Existem diferentes denominações pentecostais no Brasil, tal fato é consequência da diversidade e pluralidade do movimento. Assim, há um número crescente de igrejas com correntes diversificadas desde a doutrina, forma organizacional (governo eclesiástico), até comportamentos e maneiras de se vestir.

Uma questão importante de se observar é que o pentecostalismo é bastante dinâmico, ou seja, consegue se adaptar nas mais diversas situações, seja quanto à cultura,

26 HURLBUT, 2002, p. 222.

27 SANTOS JÚNIOR, Paulo Jonas dos. A Religiosa no Currículo de Filosofia do Estado do Espirito Santo e sua Prática Docente. 2016. 92 f. Dissertação (Mestrado) - Curso de Ciências das Religiões, Faculdade Unida de Vitória, Vitoria, 2016, p. 34.

28 MARIANO, Ricardo. Crescimento pentecostal no Brasil: fatores internos. REVER - Revista de Estudos da religião da PUC, São Paulo v. 8, n. 2, 2008 . p. 69. Disponível em: http://www.pucsp.br/rever/rv4_2008/t_mariano.pdf. Acesso em: 23 dez. 2017.

29 SANTOS JÚNIOR; ROSA, 2016, p. 249. 
forma de culto, convicções pessoais etc. ${ }^{30}$ Isso talvez explique o sucesso que tal segmento religioso consegue alcançar em ambientes em que outros segmentos de mesmo princípio, não se estabelecem. Ainda, para Mariano:

Apesar da diversidade denominacional nesse meio religioso, observa-se que, com
base nos dados do Censo Demográfico de 2000, cinco igrejas concentram nada
menos que $85 \%$ dos pentecostais do país: Assembleia de Deus ( 8.418 .154 adeptos),
Congregação Cristã no Brasil (2.489.079), Igreja Universal do Reino de Deus
(2.101.884), Igreja do Evangelho Quadrangular (1.318.812) e Igreja Pentecostal Deus
é Amor (774.827). Em 2000, a Assembleia de Deus sozinha, já quase centenária e
dividida em várias denominações, concentrava quase a metade dos pentecostais
brasileiros (47,5\%). ${ }^{31}$

Apesar do dinamismo e forte pluralidade, o culto pentecostal é bastante característico. Portanto, tais ajuntamentos solenes, em geral, seguem uma liturgia semelhante e são marcados por um fervente ardor espiritual ${ }^{32}$. Dessa forma, via de regra, as igrejas pentecostais mais conservadoras tendem a se espelhar na maior denominação pentecostal do mundo, a Assembleia de Deus; como uma das pioneiras nesse segmento, é inegável a influência assembleiana nas demais denominações pentecostais. $O$ culto na Assembleia de Deus inicia-se, geralmente, com um período de oração com os joelhos dobrados, comumente, os membros dessa denominação ao chegarem ao templo já dobram seus joelhos no lugar onde ocuparão durante a reunião e fazem suas orações particulares.

Após um breve período de oração coletiva, o pastor ou dirigente inicia o trabalho cantando alguns hinos da Harpa Cristã, em geral não mais que cinco. Então é dado a oportunidade para algum obreiro ler um trecho da Bíblia Sagrada, e posteriormente distribui-se as oportunidades entre os presentes no culto, para expressarem aquilo que sentem no coração ou louvarem a Deus com uma canção.

Após esse período de participação da membresia, é dada a oportunidade ao pregador da noite, o qual fará uma preleção aplicando os textos bíblicos aos desafios dos dias atuais. Vale lembrar que, na maioria das vezes, essa liturgia é seguida, porém o princípio básico do pentecostalismo consiste na liberdade de alterar a ritualística do culto, uma vez que, nessa doutrina, se acredita que o próprio Espírito Santo é quem governa o ritmo dos trabalhos.

Entretanto, de segunda-feira a sábado há uma série de trabalhos na igreja que fogem desse padrão litúrgico, porém não são caracterizados como "culto". Como por exemplo, o "Trabalho de Libertação", que geralmente é realizado em uma tarde e dirigido por mulheres. Nesse trabalho, a oração e a revelação divina são o foco; essa reunião atraí, em geral, um público particular, diferente daqueles que vão aos cultos no domingo, uma vez que esse público acredita que os trabalhos de libertação são mais "fortes" que outras reuniões. Liberdade essa Igualmente praticada em reuniões como: o Círculo de Oração,

\footnotetext{
MESQUIATI, 2012, p. 625.

MARIANO, 2008, p. 69.

32 MESQUIATI, 2012, p. 688.
} 
Vigília, Campanhas e outras, as quais se caracterizam pela ênfase na atuação do sobrenatural.

Porém, o pentecostalismo não vive apenas de oração e busca de experiências com o transcendente. Há, também, reuniões de estudos bíblicos e de preparação de obreiros, que apesar de não serem tão populares, são reuniões bem divulgadas, cuja participação dos fiéis nas mesmas é incentivada pelos pastores, como, por exemplo, os cultos de ensino e a escola bíblica dominical.

Esse universo do culto pentecostal, que valoriza a pessoalidade do fiel, pode explicar o surgimento de diversas denominações que, apesar de parecer um problema para aqueles que olham de fora, não se consiste em inconveniente para os membros das igrejas pentecostais.

\section{Considerações finais}

O presente artigo buscou refletir sobre o pentecostalismo no Brasil e o funcionamento de sua liturgia. Sabe-se que o pentecostalismo é vertente cristã que preza pelo dinamismo de suas reuniões, e essa característica, possibilita que o fiel tenha uma comunicação mais acessível com o divino. Dessa forma, procurou mostrar que o movimento surgiu nos Estados Unidos no século XX, por meio de reuniões de oração em que os cristãos buscavam avivamento, renovação, manifestação dos dons espirituais evidenciados pela manifestação do Espírito Santo através do dom de línguas. Além disso, o pentecostalismo despertou nos fiéis forte desejo de evangelismo.

Ao longo do artigo observou-se ainda que o pentecostalismo brasileiro, não diferente daqueles de outros países, valoriza os elementos culturais de sua população, o que pode ajudar a explicar o seu rápido e considerável crescimento, principalmente nos últimos anos. Logo, vale ressaltar o dinamismo do movimento que possibilita sua propagação, alcançando ambientes que outros grupos encontram dificuldade de acesso.

Os cultos pentecostais são bem fervorosos, despertando nos cristãos desejos de crescimento espiritual, purificação, busca pelos dons do Espírito Santo, evangelização, libertação, estudos bíblicos na tentativa de preparar obreiros, etc. Portanto, como alguns pensam, o pentecostalismo não vive somente de oração e busca de experiências espirituais. Na prática litúrgica existem os cultos de ensino e a escola bíblica dominical, na tentativa de consolidar a fé dos fiéis.

Por fim, percebe-se que o cristianismo na América-Latina, tem sido fortemente influenciado pelo pentecostalismo. Essa corrente religiosa que procura a experiência com o sagrado de maneira constante, tem encontrado no Brasil um ambiente favorável para o seu desenvolvimento, um contexto de liberdade, tolerância, pluralismo, criado inicialmente pela separação jurídica entre Igreja e Estado e estabilizado posteriormente pelas modificações da modernidade pelas quais o país passou nessa ocasião. 
Para se chegar a essas averiguações, construiu-se este artigo, que por certo servirá de enriquecimento para os estudos da religião, em especial quando o enfoque estiver relacionado ao culto pentecostal e a sua estrutura litúrgica.

\section{Referências}

BBC. Após cristãos e mulçumanos, sem-religião são $3^{\circ}$ maior grupo no mundo. Disponível em: http://www.bbc.com/portuguese/noticias/2012/12/121218_religioes_mundo_mm. Acesso em: 26 agost. 2017.

BÍBLIA. Português. Nova Bíblia Viva. João Ferreira de Almeida. São Paulo: Mundo Cristão, 2010.

CAIRNS, Earle E. O cristianismo através dos séculos: uma história da igreja cristã. Sociedade Religiosa Edições vida Nova: São Paulo, 1988.

COSTAS, Orlando. El protestantismo en América Latina hoy: Ensayos del camino. San José: INDEF, 1975.

DURKHEIM, Émile. As Formas Elementares da Vida Religiosa. São Paulo: Martins Fontes, 1996.

FONTELLES, Mauro José et al. Metodologia da pesquisa científica: diretrizes para a elaboração de um protocolo de pesquisa. Ciências Saúde, [s.i.], v. 1, n. 1, p.1-8, ago. 2009. Disponível em: <https://cienciassaude.medicina.ufg.br/up/150/o/Anexo_C8_NONAME.pd>. Acesso em: 21 dez. 2017.

GOMBRICH, Ernst Hans. A História da Arte. LTC: São Paulo. 2000.

HURLBUT, Jesse Lyman. História da Igreja Cristã. Editora Vida: São Paulo, 2002.

MARIANO, Ricardo. Crescimento pentecostal no Brasil: fatores internos. REVER - Revista de Estudos da religião da PUC, São Paulo v. 8, n. 2, p. 68-95, 2008. Disponível em: http://www.pucsp.br/rever/rv4_2008/t_mariano.pdf. Acesso em: 23 dez. 2017.

MONDIN, Battista. Curso de Filosofia. vol. 2. Paulus: São Paulo. 2014.

OLIVEIRA, David Mesquiati de; CAMPOS, Bernardo. Teologia Prática Pentecostal: particularidades, perfil e desafios no século XXI. Estudos Teológicos, São Leopoldo, v. 56, n. 2, p. 264-275, dez. 2016. Semestral. Disponível em: <http:/ / www.est.com.br/periodicos/index.php/estudos_teologicos/article/download/2 891/2662\#page=75>. Acesso em: 26 ago. 2017.

OLIVEIRA, David Mesquiati de. Diaconia Transformadora. Anais do Congresso Internacional de Teologia, São Leopoldo, v. 1, n. 1, p. 621-635, dez. 2012. Disponível em: <http://www.anais.est.edu.br/index.php/congresso/article/view/94/45>. Acesso em: 26 ago. 2017. 
SANTOS JÚNIOR, Paulo Jonas dos. A Religiosa no Currículo de Filosofia do Estado do Espirito Santo e sua Prática Docente. 2016. 92 f. Dissertação (Mestrado) - Curso de Ciências das Religiões, Faculdade Unida de Vitória, Vitoria, 2016.

SANTOS JÚNIOR, Paulo Jonas dos; ROSA, André Luís da. Experiência religiosa: da Reforma Protestante ao avivamento pentecostal. Encontros Teológicos: Reforma ontem e hoje, Florianópolis, v. 31, n. 2, p. 235-252, ago. 2016. Disponível em: <facasc.edu.br>. Acesso em: 21 dez. 2017. 